
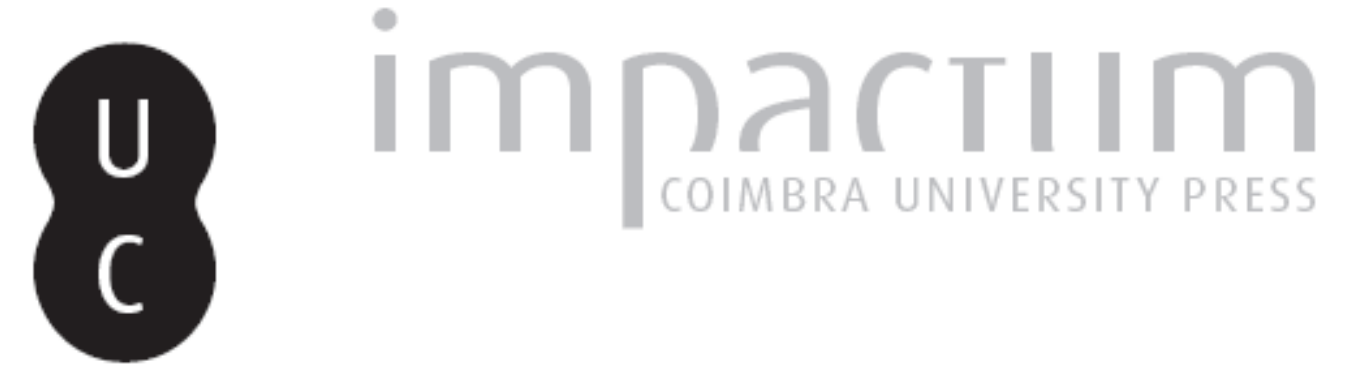

\title{
Uma breve introdução ao estudo da estética ecomidiática
}

\section{Autor(es): Kujawski, Guilherme}

Publicado por: Centro de Literatura Portuguesa; Imprensa da Universidade de Coimbra

URL persistente:

URI:http://hdl.handle.net/10316.2/37784

DOI:

DOI:http://dx.doi.org/10.14195/2182-8830_3-1_3

Accessed : $\quad$ 26-Apr-2023 11:21:46

A navegação consulta e descarregamento dos títulos inseridos nas Bibliotecas Digitais UC Digitalis, UC Pombalina e UC Impactum, pressupõem a aceitação plena e sem reservas dos Termos e Condições de Uso destas Bibliotecas Digitais, disponíveis em https://digitalis.uc.pt/pt-pt/termos.

Conforme exposto nos referidos Termos e Condições de Uso, o descarregamento de títulos de acesso restrito requer uma licença válida de autorização devendo o utilizador aceder ao(s) documento(s) a partir de um endereço de IP da instituição detentora da supramencionada licença.

Ao utilizador é apenas permitido o descarregamento para uso pessoal, pelo que o emprego do(s) título(s) descarregado(s) para outro fim, designadamente comercial, carece de autorização do respetivo autor ou editor da obra.

Na medida em que todas as obras da UC Digitalis se encontram protegidas pelo Código do Direito de Autor e Direitos Conexos e demais legislação aplicável, toda a cópia, parcial ou total, deste documento, nos casos em que é legalmente admitida, deverá conter ou fazer-se acompanhar por este aviso.

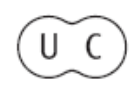




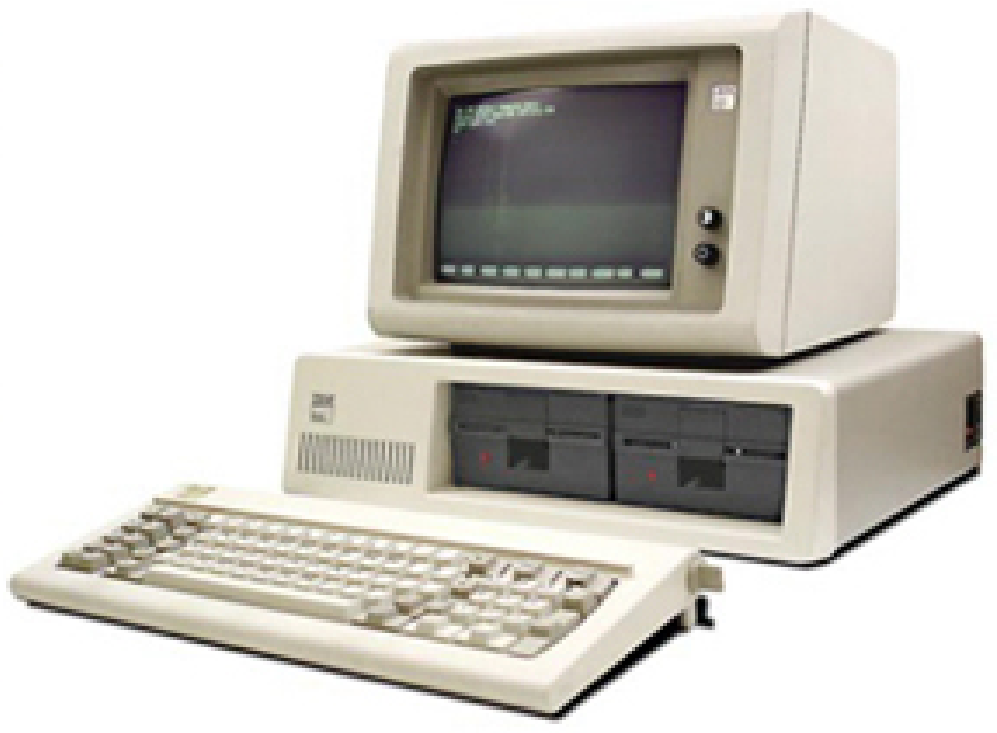

Vol. 3.1 (2015)

ISSN 2182-8830

'Artes, Média e Cultura Digital'

Paulo Silva Pereira e Pedro Serra (orgs.) 


\section{Uma Breve Introdução ao}

\section{Estudo da Estética Ecomidiática}

\section{GUILHERME KUJAWSKI}

Istituto Europeo di Design - São Paulo; Programa de Pós-Graduação em Arquitetura e Urbanismo do Instituto de Arquitetura e Urbanismo da Universidade de São Paulo

\section{Resumo}

Em linhas gerais, o artigo busca compreender a produção de uma área específica da artemídia (arte em multimeios), voltada à elaboração de uma variante da arte ecológica (tentativamente chamada de ecomidiática) que contribua com a capacidade de resiliência de infraestruturas e formulações éticas preocupadas com o futuro da humanidade e do planeta. A linha de investigação, portanto, divide-se em dois eixos: $1^{\circ}$, índices de artistas, coletivos e designers envolvidos na pesquisa de sistemas computacionais não convencionais, infraestruturas alternativas e energias renováveis; $2^{\circ}$, as relações que se estabelecem entre uma produção artística ecomidiática e conceitos filosóficos aplicados para uma teoria acerca da responsabilidade. $\mathrm{O}$ artigo associa dois ramos da filosofia (estética e ética) e, em particular, engloba áreas como ciência da computação, ecologia, energias alternativas, entre outras. Palavras-chave: artemídia; arte ambiental; cibernética; energias alternativas; filosofia da moral; resiliência tecnológica.

\section{Abstract}

In general, the article seeks to understand the production of a specific area of media art focused on a variant of Environmental art (tentatively called ecomedia aesthetics) that could contribute to technological resilience and ethical formulations concerned about the future of humanity and the planet. Therefore the research is divided into two areas: on the one hand, artists, collectives and designers involved in research on unconventional computing systems, alternative infrastructures and green energy; on the other hand, relations established between ecomedia artistic production and philosophical concepts applied to a theory of responsibility. This article combines two branches of philosophy (ethics and aesthetics) and, in particular, covers areas such as computer science, ecology, renewables, among others. Keywords: media art; environmental art; alternative energy; moral philosophy; technological resilience.

\section{Introdução}

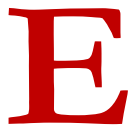

m uma análise superficial, ética e estética são dois ramos da filosofia que pareciam fadados a viver separadamente, ao menos no período entre a filosofia grega e a filosofia moderna. Ao rever a posição de ambas as disciplinas no contexto da arte contemporânea, o artigo sugere que a clivagem ao longo dos tempos é apenas ilusória. A inspiração para a pesquisa de uma produção artística ecomidiática vem de dois imperativos propostos pelo ciberneticista austríaco Heinz von Foerster: o Imperativo Estético ("se 
você deseja ver, aprenda a agir") e o Imperativo Ético (“aja sempre de maneira a aumentar o número de opções" [Foerster, 1973]). Já a palavra ecomídia, usada no título, refere-se vagamente ao termo criado por Sean Cubitt no livro de mesmo nome. Entretanto, o objetivo do teórico de mídias britânico é refletir sobre temas ambientais que vem surgindo em produtos culturais desde os anos 1980, principalmente no cinema. Pode-se dizer que, no contexto do presente artigo, ecomídia seria uma conjunção entre artemídia (Machado, 2007) e arte ambiental sem fins ativistas. ${ }^{1}$

Por certo que a dicotomia ética/estética proposta no presente artigo mereceria como complemento uma abordagem política. No contexto da crise ambiental, faz sentido refletir sobre a relação entre as duas disciplinas filosóficas e considerar as estruturas políticas subjacentes. Porém, nos é imposto antecipar um caveat lector aos mais politizados: estamos tratando de uma forma de arte ambiental ajustada aos tempos de crise ecológica, portanto nos parece que previlegiar a abordagem estética é estratégia vital, já que a mesma se entrelaça com a ideia de percep̧̧ão ao mundo circundante (Morton, 2007: 26), chamado pelos ambientalistas de meio ambiente. Nesse sentido, a abordagem estética e ética, e não a política, nos parece ser a mais apta para levantar questões artísticas relacionadas à ecologia.

No âmbito do artigo, o imperativo estético será evidenciado por meio de uma breve análise de iniciativas que estão investigando energias alternativas e novas formas não convencionais de computação, destacando modelos inspirados na natureza, biologia, física, mecânica e química. Designers e artistas como Martin Howse, Carlos Castellanos, Antony Hall, Ralf Baecker, Naomi Kizhner e muitos outros pesquisam modelos considerados hoje anacrônicos, como a computação analógica, mas também áreas avançadas, como a computação de matérias biológicas e programáveis. Por exemplo, o computador telúrico do artista britânico Martin Howse é uma máquina sem fios, sem componentes e sem abstrações, operando apenas com elementos extraídos do solo. De acordo com esta abordagem "materialista" da computação, alguns artistas de artemídia estão recorrendo a técnicas não convencionais, como eletro-cristalizações, transmissão de rádio de cristal e computação de inspiração biológica.

Já o imperativo ético será orientado pela afirmação do filósofo francês Jean-Pierre Dupuy: se quisermos enfrentar adequadamente a ameaça de uma possível catástrofe ambiental, é preciso quebrar uma noção histórica da filosofia moral e abraçar uma ética do futuro [Dupuy, 2011], um conjunto de preceitos derivados de uma responsabilidade direta para com as gerações futuras. A conclusão parcial é a seguinte: se as atuais ontologias tecnológicas estão aparentemente conduzindo a humanidade para uma condição de risco ambiental (os dispositivos eletrônicos não são sustentáveis, os data centers

${ }^{1} \mathrm{Um}$ exemplo de arte tecnoecológica com objetivos denunciatórios é o trabalho do coletivo francês HeHe, formado por Helen Evans and Heiko Hansen. 
consomem energia em demasia, etc.), então a estética ecomidiática poderia apresentar opções que, apesar de não serem aplicáveis no presente momento, podem servir de inspiração e fundamento para futuras situações de resiliência, principalmente às relacionadas com a reconstrução de sistemas de comunicação e informação.

\section{Resiliência versus sustentabilidade}

O termo resiliência, no contexto do presente artigo, descreve um conjunto de alternativas para lidar, de forma sistêmica, na reconstrução de infraestruturas de comunicação e informação. ${ }^{2}$ No que tange ao aspecto psicológico e emocional, a noção de resiliência seria por demais pessimista, enquanto a de sustentabilidade ofereceria certo alento, segundo o senso comum. Mas esta é uma análise reducionista. Primeiro é necessário construir um aparato crítico para a noção de sustentabilidade e, por extensão, para a teoria da resiliência, propondo a análise de cada um dos termos na qual são compensadas as deficiências de um com as qualidades do outro, e vice-versa. Por enquanto, na arena do pensamento ecológico, nota-se uma polaridade, ${ }^{3}$ com um embate entre os defensores da resiliência e os da sustentabilidade, ambos com aversão ao seu "oposto". Para evitar possíveis aporias, propomos uma união entre a crítica à crítica da resiliência e a crítica à crítica da sustentabilidade.

A primeira tarefa de nosso intento é modular o excessivo peso econômico dado à noção de sustentabilidade, com a qual se juntam, diga-se, outros setores, como o político, o ecológico e o cultural. Daí o princípio da sustentabilidade remontar diretamente ao desenvolvimento sustentável, modelo de crescimento supostamente garantidor de um estado estacionário equilibrado; de qualquer forma, é quase impossível dissociar a ideia de desenvolvimento com a de progresso e, principalmente, com a de manutenção de recursos naturais, ou seja, uma indústria que carrega o selo da sustentabilidade é uma empresa que, ao menos em tese, oferece uma contrapartida compensatória ao meio ambiente, garantindo ao menos a contínua disponibilidade de capital natural. Mas isso não é o suficiente. Faz-se necessário incluir na equação da sustentabilidade o conceito de resiliência, mas em sua acepção ecológica, que "é a quantidade de perturbação que um sistema é capaz de absorver sem alterar seus domínios de estabilidade" (Gunderson, 2000).

A resiliência da qual falamos é também uma resiliência crítica, quase uma derivação da crítica ecológica. O intento é realizar uma crítica à noção de sustentabilidade e à teoria da resiliência por meio da criação de uma narrativa

2 Ver o relatório do IMMI. McCarthy, Smári e Eleanor Saitta (2012). "Islands of Resilience Comparative Model for Energy, Connectivity and Jurisdiction." International Modern Media Institute. 27 de Agosto de 2014. http://www.greensefa.eu/fileadmin/dam/Documents/Studies/islands_of_resilience.pdf

${ }^{3}$ Ver Rees, 2014. 
capaz de alterar uma corrente percepção de mundo. Tal narrativa, por sua vez, toma a forma de expressões estéticas (em nosso caso, no âmbito das artes visuais contemporâneas), ou seja, a nossa estratégia vale-se de um elemento perceptivo associado a uma ética da ação. Por exemplo, é possível aplicar o conceito "amplificação organizadora", proposto por Simondon, na prática da resiliência crítica, usando a sustentabilidade e a resiliência não como elementos antagônicos, mas diametralmente complementares, como os dois olhos da visão bifocal humana. ${ }^{4} \mathrm{O}$ estético, em complô com o ético, segundo tal crítica, é um ato político por natureza, pois subverteria as percepções - e não as ideologias. As obras comentadas no artigo são índices que não perfazem um conjunto propriamente dito. São índices na acepção semiótica, ou seja, indícios de algo ou alguma coisa.

\section{Arte na era Antropocena}

As atuais denúncias da crise ecológica não são o resultado de falta de otimismo: a matriz do problema é mais real, reside nas leis da termodinâmica e na incompatibilidade entre um crescimento econômico desenfreado e os limites rígidos de um planeta finito. Um evento acontecido no segundo semestre de 2014, aparentemente sem maiores significados, fornece algumas pistas: um incêndio retirou de operação uma enorme "mineradora" de bitcoins na Tailândia (bitcoin é um criptomoeda independente de qualquer autoridade central, cuja criação demanda um poder de processamento brutal de computadores espalhados pelo mundo), alterando significativamente a capacidade global do sistema de confecção da moeda virtual, uma produção que demanda quantidades brutais de energia elétrica. Somando a esse fato as previsões de aumento de consumo médio de energia por pessoa até 2040, pode-se inferir que a humanidade está ingressando em uma perigosa situação de retroalimentação positiva: mais consumo do que produção. A cibernética, ciência interdisciplinar surgida nos EUA no contexto da segunda guerra mundial, distingue as retroalimentações negativas das positivas. Enquanto a primeira é a reação pela qual um sistema (biológico, mecânico, político, etc.) reverte uma mudança indesejada, mantendo estáveis as variáveis que garantem seu equilíbrio (homeostase), a segunda amplifica o fator de mudança, produzindo efeitos desestabilizadores. Aquecimento global, engarrafamentos de automóveis e

\footnotetext{
${ }^{4}$ Esteban, Pablo Rodrígues. "Comunicación e información: la refundación de la tecnología, las ciencias naturales y las ciencias sociales en Gilbert Simondon”, artigo produzido para o simpósio "Informação, tecnicidade, individuação: a urgência do pensamento de Gilbert Simondon", ocorrido em 2012 na Universidade Estadual de Campinas (UNICAMP). O pensador argentino descreve assim a organização amplificadora, se valendo do mesmo exemplo usado por Gilbert Simondon, o da percepção binocular: "Las imágenes de cada ojo están en relación de disparidad, pero esa disparidad es la condición necesaria para que aparezcan planos sucesivos, sin que ello signifique que los elementos dispares se fundan."
} 
guerras assimétricas são alguns exemplos de sistemas que reforçam circuitos contrários à manutenção de um equilíbrio vital. $\mathrm{O}$ entendimento desse mecanismo autodestrutivo pode inspirar ações que contribuam com a sua moderação ou mesmo anulação.

Nesse sentido, a resiliência dentro do contexto da estética ecomidiática tem mais a ver com a reabilitação do que para a recuperação de um dado sistema. Tanto o corpo sócio-técnico, como o seu entorno, estão sofrendo os efeitos da retroalimentação positiva, exatamente o mesmo fenômeno que coloca, por exemplo, as geleiras em processo de retração. A reabilitação reduziria os excessos (excesso de informação, excesso da Lei de Moore, excesso da Lei de White, na qual a "cultura evolui à medida que é aumentada anualmente a quantidade de energia per capita consumida"), reajustando o corpo sócio-técnico à uma realidade termodinâmica. A resiliência, nesse contexto, reabilitaria o corpo social (e sócio-técnico) em pleno percurso histórico, durante o seu processo de individuação (ou transindividuação, como queria o filósofo francês Gilbert Simondon). Em termos energéticos e de infraestrutura, visa adaptar o corpo sócio-técnico às tecnologias ad-hoc, low tech, low energy, decentralizadas, não convencionais, ou mesmo retro futuristas (Greer, 2009).

O futuro distópico já é parte integrante do imaginário popular e a cultura da catástrofe vem ganhando destaque nas mídias: filmes, seriados de TV, livros, além de uma quantidade considerável de conteúdo relacionado ao chamado sobrevivencialismo, a crença de que seres humanos devem passar antecipadamente por situações de autossuficiência com o objetivo de se preparar para rupturas sociais e econômicas provocadas por desastres naturais (ou não naturais). Kits de sobrevivência, guias e manuais de sistemas autônomos não ligados às redes de telecomunicações e do setor elétrico, planos de contingência e de recuperação, e uma infinidade de conteúdos relacionados ao tema estão disponíveis na Internet. $\mathrm{O}$ nosso objetivo, porém, não é esboçar um manual de crise energética para gerações do porvir, mas levantar a seguinte questão: pode uma determinada produção artística servir de parâmetro para a futura reconstrução de uma infraestrutura tecnológica devastada e, ao mesmo tempo, refundar uma ordem moral obsoleta?

O problema acessório da questão do parágrafo anterior é: a humanidade conseguiu construir a maior infraestrutura tecnológica de toda a sua história, mas parece ser incapaz de realizar projeções futuras acerca de sua manutenção e condições socio-técnicas. Dada a declaração do problema, levantamos a seguinte hipótese: a arte ecomidiática comportaria um modelo de resiliência e, paralelamente, uma teoria moral consequencialista ajustada aos novos tempos. Daí a necessidade de se estabelecer de largada a desvinculação da estética ecomidiática de uma arte pós-digital que seja exclusivamente imagética, puramente representacional, uma arte que, predominantemente, ignora o papel da crítica na era Antropocena, termo usado por alguns cientistas para descrever o período geológico mais recente do Planeta Terra, no qual os humanos interferem 
diretamente no bioma, assim como as algas interferiram no período Hadeano, oxigenando a atmosfera.

Os praticantes da arte ecomidiática também pretendem, direta ou indiretamente, esboçar um entendimento crítico do fatalismo (Dupuy, 2013) e evidenciar, por meio de um certo tipo de uma expressão artística, para a excessiva dependência da sociedade contemporânea de dispositivos digitais e energias não renováveis. Uma de suas estratégias é a pesquisa de sistemas de computação não convencional, tanto para fins científicos como artísticos. Grosso modo, as investigações sobre o tema ainda são incipientes, assim como considerações sobre a renovação de uma ética presentista que não leva em consideração os impactos dos atuais sistemas de exploração e produção na natureza e gerações futuras (Jonas, 2011). A meta dos artistas ecomidiáticos é trazer à tona o primeiro tema por via da arte contemporânea e, o segundo, por meio de um "catastrofismo esclarecido" (Dupuy, 2013).

\section{Princípios da estética ecomidiática}

No universo especulativo proposto neste artigo a computação não é exclusividade de máquinas eletrônico-digitais. Entretanto, não descarta iniciativas digitais não eletrônicas (como o computador hidráulico de J. R. Greenwood, pesquisador do MIT [Angrist, 1964]); nem iniciativas eletrônicas não digitais como o computador eletroquímico de Gordon Pask [Cariani, 1993]). Na ciência, os computadores analógicos e biológicos caíram em descrédito devido à Lei de Moore; mas há experiências que merecem ser revisitadas em tempos de crise ecológica. Na década de 1960 o cientista britânico Stafford Beer propôs um computador orgânico formado por uma colônia de crustáceos de uma lagoa, um meio de transformar informações de um ecossistema entrópico em soluções para problemas inesperados em uma fábrica. ${ }^{5}$ Já o seu conterrâneo Gordon Pask, no campo da computação não convencional, preferia os computadores químicos, sendo o processo de cristalização iniciado pela eletrólise um sistema dinâmico capaz de transformar elementos e realizar computações. Tipos de soluções inimagináveis em nossa era de tecnologias velozes de ponta, mas perfeitamente plausíveis em um mundo póscatástrofe.

Atualmente, há muitas pesquisas que interpretam os processos naturais em termos computacionais. Por exemplo, cientistas da Universidade de Kobe, no Japão, construíram um computador inspirados por um modelo bastante singular: o comportamento em forma de enxameação dos caranguejos soldado (Mictyris longicarpus), animais capazes de implementar portas lógicas quando colocados num ambiente geometricamente limitado. Outro

${ }^{5}$ Ver Fortune, Stephen (2013). "Meet Your New Wetware Manager." 9 de julho de 2014. http://www.thestate.ae/meet-your-new-wetware-manager 
exemplo são os fungos limosos (Physarum polycephalum), organismos que antigamente pensava-se ser uma ramificação de fungos do tipo mofo, mas que hoje são usados para estabelecer redes protoplasmáticas, agindo como computadores amorfos maciçamente paralelos, com entradas distribuídas, processamento de informação descentralizada e de tomada de decisão. Pesquisadores descobriram que a criatura realiza computações internas para descobrir trajetórias eficientes entre dois pontos, com o objetivo de coletar alimentos. O mesmo modelo está sendo usado para estabelecer percursos de estradas de rodagem, mas pode, em um cenário pós-catástrofe, ser aplicado para o restabelecimento de pontos de uma rede de telefonia construída sobre cercas de arame farpado, como o fez Cassius Alley em 1893.

No campo da artemídia há diversas evidências de uma produção baseada em computação não convencional que aponta para a questão da resiliência tecnológica e do lixo eletrônico. Por exemplo, uma experiência de reuso alternativo de placas de circuito impresso e discos rígidos aconteceu durante a exposição Crystal World, parte do CTM, em Berlin (evento paralelo ao transmediale de 2012). ${ }^{6}$ A oficina, coordenada pelos britânicos Martin Howse, Ryan Jordan e Jonathan Kemp, revelou ao público as forças da geologia milenar incrustadas em dispositivos e peças ordinárias de computadores. As ações dos artistas fazem parte de um projeto mais amplo e complexo, chamado The Earthcodes Project, uma série de experimentos envolvendo radioestesia, um sistema operacional inicializado por correntes telúricas (o que Howse chama de land art computacional), o estudo dos efeitos do campo geomagnético sobre a consciência humana, entre outros tópicos.

As atividades das oficinas no CTM incluíram procedimentos de precipitação de minerais comuns e terras raras, além de geologia sintética e cristalografia indutiva. Em uma das performances os artistas produziram fulguritos, corpos vitrificados devido à fusão da sílica por descarga elétrica. Também provocaram o aparecimento de termites (ou termitas), um tipo de reação aluminotérmica em que o alumínio é oxidado por um outro metal, geralmente o óxido de ferro. Fornos de micro-ondas transformados em cadinhos forjaram silício em pó a partir de areia de quartzo aquecido com pó de magnésio. $\mathrm{O}$ nitrato de prata - além de ferro, cobre, fósforo, boro, tântalo e outros tantos metais — foi extraído por eletrólise química das placas de circuito impresso e usado na confecção de pequenas esculturas metálicas. Para estes artistas, entre se adaptar às realidades da natureza, ou controlá-la, optase por inventar novas estruturas que a façam evoluir de várias formas, uma premissa da estética ecomidiática.

O clímax das experiências de Howse e seus parceiros foi a construção de um "computador telúrico", o chamado Computador da Terra. O artista reflete sobre a tecnicalidade desse dispositivo na edição parte do evento no CTM,

${ }^{6}$ Ver o wiki do projeto The Crystal World Open Laboratory. 9 de julho de 2014. http:// crystal.xxn.org.uk/wiki/doku.php 
uma compilação de textos de ficção (como The Crystal World, de J. G. Ballard) e materiais científicos arcanos, como o tratado de al-Bīrūnī sobre a malaquita (esse sábio árabe rejeitava noção de transmutação, embora admitia na natureza o crescimento e a transformação gradual de metais em ouro), um livro de história da química na Índia, receitas tibetanas de formação de metais (segundo consta o ouro seria formado pela mistura, em partes iguais, de arsênico, mica, sobhir e kakusatha), técnicas e dados sobre reciclagem de componentes eletrônicos na China, e outros textos que sustentam a narrativa criptogeológica de Howse. ${ }^{7} \mathrm{O}$ computador telúrico é, na verdade, uma bateria feita de cobre reciclado e zinco disposta sobre uma bandeja de nitrato de prata e lama, tudo coberto por duas tiras de cobre.

Além da subjacente noção de resiliência computacional explorada por Howse, outro importante componente da estética ecomidiática integra energias alternativas, principalmente a bioenergia. Rasa e Raitis Smits, em conjunto com Martins Ratniks, artistas de Letônia, realizaram em 2013 o projeto Biotricity No.5, trabalho baseado em células de combustível movidas a bactérias. ${ }^{8}$ Uma célula de combustível é uma célula eletroquímica em que os agentes da combustão e geração de energia são renovados continuamente, ao contrário das pilhas e baterias. Ao produzir prótons de hidrogênio, as bactérias liberam elétrons, que são absorvidos pelo oxigênio contido pela ponte salina que liga o recipiente do lodo ao recepiente de água limpa. A obra, e as oficinas correspondentes na Holanda, apontam para as infraestruturas energéticas do futuro, tais como energia peer-to-peer, microrredes, etc.

Outro exemplo nessa linha propõe a iluminação da cidade em miniatura de Schöppingen no século XVII com células de combustível movidas a bactérias. ${ }^{9} \mathrm{O}$ objetivo, segundo o artista Mick Lorusso (que trabalhou em conjunto com pesquisadores do Laboratório de Ecologia Microbiana e Tecnologia em Ghent), é criar uma analogia entre comunidades de bactérias, uma das mais antigas formas de vida na Terra, e as comunidades humanas, aglomeradas majoritariamente em complexos urbanos. Na Schöppingen microbiana, bactérias também geram correntes elétricas ao quebrar carboidratos em moléculas menores, ou seja, dióxido de carbono e hidrogênio. Biofilmes grudados sobre eletrodos de grafite finalizam a mágica da condutividade e a geração de eletricidade. Em uma última aferição, a cidade bacteriana estava produzindo 0,4 Volts, com cerca de 5 mili-amperes no período de um mês.

\footnotetext{
${ }^{7}$ Ver The Crystal World Reader and Manual of Speculative Apparatus [v.01]. 9 de julho de 2014. http://crystal.xxn.org.uk/wiki/doku.php?id=the_crystal_world:ctm12:reader 8 Ver o vídeo explicativo BIOTRICITY. Bacteria Battery No 5. 9 de julho de 2014. http://vimeo.com/51380366

${ }^{9}$ Ver Lorusso, Mick (2012). "The Light of Microbial Schöppingen." 28 de agosto de 2014. http:// tinyurl.com/ovjdwh2
} 


\section{A terceira via}

Em vista na iminente catástrofe ecológica que se avizinha, parece-nos que hoje há apenas duas possíveis reações: negação ou melancolia. Mas existe uma terceira via, cujas linhas gerais foram descritas pelo pesquisador estadunidense Adam Flynn em seu manifesto solarpunk (Flynn, 2014). Ao contrário do que imaginavam os arautos do cyberpunk, movimento de renovação da ficção científica iniciada em meados dos anos 1980 nos EUA, o futuro não necessariamente tem características apocalípticas. A primeira atitude sugerida pelos anarco-primitivistas da terceira via é impelir a sociedade industrial a um processo de desaceleração tecnológica, isto é, apropriar-se das conquistas técnicas do capitalismo industrial para fins próprios, sem apelar para o desgastado conceito de sustentabilidade. Segundo eles, o desenvolvimento industrial chegou ao seu ápice, portanto, faz-se necessário investir no desaceleracionismo, uma diminuição drástica do ritmo de produção tecnológica proprietária, vítima mortal dos sistemas escaláveis e, consequentemente, da lei da utilidade marginal, a qual indica que, em uma relação econômica, a utilidade de um bem decresce à medida em que se consome mais que uma unidade do mesmo. A partir desse ponto, surge a lei da inutilidade marginal, segundo o economista Herman Daly.

A desaceleração também é favorável às tecnologias low tech, mais próximas às tradições artesanais, às funções técnicas de funcionamento e aos métodos decentralizados. Os solarpunks (e, em certa medida, os estetas ecomidiáticos) são visionários e poetas tecnológicos que acreditam ser possível transformar os jardins de uma ecovila em um computador analógico. Por exemplo, quando temos a visão panorâmica dos jardins da Villa d'Este, palácio italiano situado em Tivoli, próximo de Roma, quase que vislumbramos uma placa de circuito impresso natural, ou seja, entrevemos os circuitos naturais de um proto-supercomputador analógico formado por sistemas de repuxo, bombas de força, rodas d'água, tanques de decantação, reservatórios cercados por parterres, canais, aquedutos, fontes e canteiros. É sempre oportuno lembrar que o termo analógico se refere ao fato de as grandezas físicas contínuas dentro do computador poderem representar diretamente uma grandeza também contínua do sistema físico real; está em contato direto com a natureza. Em contraposição, num computador digital todas as grandezas de estados elementares resultam em um sistema baseado em um tempo discreto, descontínuo.

\section{A forma segue a função técnica}

O entendimento de que "a forma segue a função" é cria do arquiteto estadunidense Louis Sullivan (1896), o qual foi posteriormente popularizado na famosa máxima modernista, ou seja, considerações estéticas devem ser 
secundárias às funcionais. $\mathrm{Na}$ prática do design crítico, programa concebido por acadêmicos do Royal College of Art de Londres, a função vai além do aspecto físico e técnico do objeto, da otimização, da eficiência e utilidade, para operar em modos sociais, psicológicos e culturais, daí o seu aspecto "estético". É talvez compatível com a estética ecomidiática e com algumas noções de Gilbert Simondon, que criticava as metafísicas de imposição formativa à matéria amorfa (Simondon, 2009). Para o filósofo francês, faz-se necessário converter a noção de forma em informação, ou seja, o objeto técnico deve conotar um processo, uma operação, uma série em formação. Assim, quando o objeto técnico é colocado em ação, em conformidade com sua essência, ele deixa de ser meramente uma ferramenta ou um instrumento, tornando-se uma relação de acoplamento direto do pensamento humano com a natureza em processo de transformação.

O termo modernista surgiu originalmente para desbancar o fenômeno da decoração. Há pontos positivos, como apontados acima, e negativos, como o excessivo funcionalismo resultante. É benéfico ao sugerir que o design deve estar sempre relacionado à função técnica do objeto, ao seu funcionamento. Também sugere que a forma deve não apenas seguir a função do objeto, mas também estar integrada à ela. Mas na atual realidade tecnológica, forma e função voltaram a se separar, não em razão do combate ao ornamento, como antigamente, mas em razão da chamada funcionalidade, uma garantia de que o produto deve operar tal como foi especificado pelo designer. Nota-se então o pior dos mundos possíveis: o hermetismo do funcionamento de um lado e a libertação formal do outro (Michaud, 2012). Ou seja, a função técnica de um objeto passou a ser menos importante que os fatores ergométricos e as normas de uso. Com efeito, a indústria tende a produzir cada vez mais objetos inacessíveis, não consertáveis e inadaptáveis. Felizmente, alguns praticantes do design crítico e da ecomídia estão subvertendo tais vícios e criando uma estética na qual forma e função voltam a se atrelar.

É o caso do coletivo esloveno Re-do Studio que, durante a 24a Bienal de Design de Liubliana, na Eslovênia, apresentaram o projeto Engine Block, um motor multifuncional para situações pós-catástrofe. Nota-se no vídeo de introdução ao objeto ${ }^{10}$ uma estética cinematográfica pós-apocalíptica, semelhante àquela explorada por George Miller no filme Mad Max (1979) ou no livro A Estrada (2006), de Cormac McCarthy. Mas o que mais nos interessa no objeto técnico criado pelo grupo esloveno são os conceitos subversivos de forma e função, característicos da estética ecomidiática. No vídeo, o protagonista, que, segundo a narrativa, prefere "criar suas próprias ferramentas ao invés de viver numa caverna como seus antepassados", sugere que o uso do objeto técnico em questão determina a sua forma, isto é, o tipo de uso reconfigura a forma e, consequentemente, a sua função técnica, seu funcio-

${ }^{10}$ Ver o vídeo Engine Block, uma produção do coletivo de designers eslovenos Re-do Studio. 29 de dezembro de 2013. http://vimeo.com/105982327 
namento. Um único objeto técnico se transforma em motor de motocicleta, motor de popa de barco, motor de serra elétrica e assim por diante. Tal "multifuncionalidade" revela outras facetas de seu funcionamento, que é antihermético e, o que é mais importante nesse caso, a função e a forma estão intimamente integradas. No caso de Engine Block, além de a forma coincidir com a função técnica (o funcionamento), também comporta duas características essenciais: o uso privilegia a função (e não o contrário) e o seu funcionamento é totalmente aberto.

\section{Breves fundamentos filosóficos}

Na chamada de trabalhos para o simpósio afterglow do transmediale 2014, Tatiana Bazzichelli adota um tom catastrofista: "a cultura digital está cada vez mais se tornando um deserto pós-apocalíptico governado por poucos líderes de clãs poderosos". ${ }^{11}$ Apesar do cenário lúgubre, a curadora do simpósio reconhece ao término da chamada que o novo ser da cultura técnica está prestes a surgir. Não tanto catastrofista, talvez "catastrofista racional", o cenário especulativo proposto no presente artigo é algo que se enquadra livremente na sexta cláusula do Manifesto do Engenheiro Crítico, ${ }^{12}$ do artista-hacker Julian Oliver, que descreve os protagonistas do novo materialismo filosófico: objetos técnicos, corpos, agentes, forças e redes. Tem também alguma relação com o cenário pós-digital sugerido pelo pesquisador brasileiro Felipe Fonseca, composto pela internet das coisas, computação física, fabricação doméstica, mídia locativa e afins (Fonseca, 2011). Porém, é preciso observar de antemão que a estética ecomidiática não tem conexões com a Nova Estética, lançada por James Bridle no evento South By South West de 2012, "tendência" que prospecta afloramentos do digital no mundo analógico.

Em termos éticos, o artista ecomidiático não desvia a sua atenção do pior cenário, qual seja, o possível retorno da humanidade ao mundo analógico, seja por motivos catastróficos naturais, ou não. A maioria dos artistas da artemídia continua celebrando os dispositivos eletrônico-digitais, sem se preocupar com uma ética para a sociedade tecnológica do século XXI. Talvez uma estética com preocupações éticas de responsabilidade esteja sendo desenvolvida em Südthüringer-Wald-Institut, ${ }^{13}$ uma organização de pesquisa independente cuja sede foi instalada em uma caverna situada a 200 metros de

11 Ver transmediale 2014 - Call for Works. 9 de julho de 2013. http:/ / www.transmediale.de/content/transmediale-2014-call-for-works

12 Ver "The Critical Engineering Working Group", por Julian Oliver, Gordan Savičić e Danja Vasiliev. 9 de julho de 2013. http:/ / criticalengineering.org

13 Ver o resumo do paper apresentado por integrantes do instituto no programa do xCoAx2013 - Computation, Communication, Aesthetics and X. 10 de julho de 2013. http://2013.xcoax.org/\#p35 
profundidade sob uma floresta da Turíngia, na antiga Alemanha Oriental. Incorporando o ethos do "esperar pelo melhor é esperar pelo pior", o trabalho do Instituto pesquisa o potencial criativo da tecnocracia apocalíptica, mas tudo a serviço de um funcionalismo pragmático. A negação da catástrofe, segundo seus integrantes, apenas nos imobiliza.

Digamos que essa forma de estética ecomidiática aponta para uma ética do futuro, ou ao menos para um hiperpresente problemático que se manifesta como um pré-futuro. Portanto, a ética do futuro é aquela que "consiste em se projetar na pós-catástrofe e em ver retrospectivamente nesta um acontecimento ao mesmo tempo necessário e improvável" (Dupuy, 2013), ou seja, é permitir que o pior cenário seja elaborado a partir de uma hipótese não confirmada que, devido ao risco iminente, pode ganhar estatuto de validade. Desta forma, é possível buscar um diálogo entre catastrofistas e utópicos na Sala de Situações do Sistema Terra, desde que o corrente modelo da precaução, impregnado pela noção do custo-benefício, seja substituído por uma prudência racional. Por exemplo, na precaução o piloto entra no avião sem acreditar que um acidente possa vir a ocorrer; na prudência racional, ele entra na cabine "certo" de que um acidente vai ocorrer, portanto ficará duas vezes mais atento (e mais eficiente) no sentido de minimizar a possibilidade de perda total e garantir, em caso de emergência, o menor dos males possíveis, pousando o avião em segurança. É a única expectativa razoável nos dias de hoje. Em suma, é tornar a catástrofe ecológica tão crível e factível quanto a ameaça nuclear durante a Guerra Fria. Assim a humanidade deveria se comportar perante o destino de seus descendentes.

Digamos que essa noção ética também aponte para uma estética da catástrofe nas mãos de artistas que sabem alternar o "sempre-já" com o "aqui-agora". No geral, a obra de tais artistas provoca ações da parte do observador-participante, tais como imaginar técnicas ancestrais da ciência ou aplicações na vida real das receitas dispostas nos textos da Biblioteca do Sobrevivente. ${ }^{14}$ Esse impulso, essa intenção técnica, é quase uma constante na história da humanidade; ou seja, a tecnicidade primitiva é mantida por mais que ocorram mudanças de paradigmas, e a sua presença surge de tempos em tempos, como as técnicas de laminação de espadas desenvolvidas em diferentes lugares, e em diferentes épocas (Simondon, 2009). A tecnicidade não é a técnica como "destino", como queria Heiddeger, mas sim uma intenção atemporal inerente ao ser humano, como a confecção de ferramentas e a crença em entidades divinas.

14 Ver Survivor Library or... How to Survive when the Technology Doesn't. 29 de dezembro de 2013. http://blog.survivorlibrary.com 


\section{Considerações finais}

A atualidade do hipotético programa pode ser encontrada em vários exemplos na sociedade tecnológica e industrial contemporânea. A IDEO, famosa empresa norte-americana de design e consultoria, lançou recentemente o projeto City $72,{ }^{15}$ uma plataforma voltada para municipalidades de todo o planeta interessadas em obter um plano geral de preparação para emergências, projetado para organizar os cidadãos locais para as primeiras 72 horas após um desastre, seja natural ou não. Por que uma empresa associada a questões de inovação, design thinking e criatividade tenha se envolvido em um projeto aparentemente "pessimista" e mesmo "negativo"? Talvez o exemplo sugira um padrão ou a urgência de se investir em tais iniciativas.

Os índices elencados no artigo invocam uma forma de arte que celebra as antigas capacidades técnicas, ou seja, o retorno ao conhecimento prático (não contemplativo) e o modo de fazer as coisas. Celebra, desta feita, a reunião de techné, poeisis e episteme em um único programa de ação que ainda contém um princípio ético de responsabilidade. O programa promove também a estética da não distância, que vai contra o distanciamento exigido pelo sublime kantiano, ou seja, é uma estética do colapso de dualismos, motivada por uma resiliência "sócio-técnico-ecológica" preparada para enfrentar as etapas sucessivas de estados de equilíbrio, intercaladas por períodos de grande instabilidade, além de definir o modo de recuperação de um sistema perturbado, em nosso caso, das tecnologias de informação e comunicação.

A lista de artistas trabalhando na intersecção entre a estética ecomidiática e a ética do futuro não é exaustiva, e portanto merece uma prospecção complementar. Quando Heinz von Foerster esclarece que o ato de olhar é "construído" - um contemplar que poderia ser diagramado por Lacan, para quem o trapézio formado pelo cruzamento da observação e da observação da observação é projetado sobre a "tela" do Real - ele estava se referindo a uma certa proatividade do observador. Mas o agir do qual estamos tratando não se restringe ao olhar, e implica numa interferência mais abrangente no mundo real. Nesse sentido, artistas deveriam aumentar o leque de opções para um possível cenário pós-catátrofe, e não investir em relações de dependência para com um mundo puramente digital e eletrônico. É preciso que os artistas contemporâneos se preocupem também com a questão dos recursos energéticos, já que a tecnologia das baterias, por exemplo, não tem evoluido tanto como as tecnologias de big data. Por enquanto os praticantes da estética ecomidiática poderiam se questionar: quando se precipitará a computação em nuvem na forma de uma avassaladora tempestade?

${ }^{15}$ Ver http:/ / toolkit.sf72.org. 29 de agosto de 2014. 


\section{Referências}

AKL, Selim G. (2006). "Conventional or unconventional: Is any computer universal? Rigueurs et revers du calcul universel.” From utopian to genuine unconventional computers: splendeurs et miseres du calcul peu usuel. Coord. Andrew Adamatzky e Christof Teuscher. Frome: Luniver Press. 101-136.

ANGRIST, Stanley W. (1964). "Fluid control devices." Scientific American 211.6: 80-88.

BARTLETT, Philip (2008). Bioelectrochemistry: fundamentals, experimental techniques and applications. Wiley Online Library.

BECK, Ulrich (1992). Risk society: towards a new modernity. Nova York: SAGE Publications Ltd.

BROWN, Andrew (2014). Art \& Ecology Now. Reino Unido: Thames \& Hudson.

CARIANI, Peter (1993). "To Evolve an Ear: Epistemological Implications of Gordon Pask's Electrochemical Devices.” Systems Research 10.3: 19-33.

CUBBITT, Sean (2005). Ecomedia. Amsterdã, Nova York: Rodolfi.

DUPUY, Jean-Pierre (2001). O Tempo das Catástrofes: Quando o Impossivel é Uma Certeza. São Paulo: Realizações Editora.

FLYNN, Adam (2014). "Solarpunk: Notes toward a manifesto." Hieroglyph. 20 de dezembro de 2013.

http://hieroglyph.asu.edu/2014/09/solarpunk-notes-toward-amanifesto

FOERSTER, Heinz von (1973). On Constructing a Reality. Virginia Polytechnic Institute: Virginia, US.

(1991). "Ethics and Second-Order Cybernetics." Systemes, Ethiques: Perspectives en Therapie Familiale. Paris: ESF Editeur.

FONSECA, Felipe (2011). "Laboratórios do Pós-Digital." baixacultura. 9 de julho de 2013.

http://baixacultura.org/biblioteca/3-livros/laboratorio-do-pos-digital/

GORZ, Andre (1980). Ecology as Politics. Québec: Black Rose Books.

GREER, John Michael (2009). The Ecotechnic Future: Envisioning a Post-Peak World. New Society Publishers.

GROVE, Kevin (2014). "Agency, Affect, and the Immunological Politics of Disaster Resilience." Environment and Planning D: Society and Space 32: 240256.

GUNDERSON, Lance H. (2000). "Ecological Resilience.” Theory and Application. Annual Review of Ecology and Systematics 31.1: 425-439.

ILLICH, Ivan (2000). Energy and Equity. Reino Unido: Marion Boyars Publishers.

JONAS, Hans (2011). O Princípio da Responsabilidade. Rio de Janeiro: editora Contraponto.

KAUFFMAN, Stuart (2008). Reinventing the Sacred: the Science of Complexity and the Emergence of a Natural Divinity. Nova York: Basic Books. 
LEVINAS, Emmanuel (1985). Ethics and Infinity. Pittsburgh: Duquesne University Press.

MACHADO, Arlindo (2007). Arte e Mídia. São Paulo: Zahar.

MICHAUD, Yves. (2012). "The Aesthetics of Gilbert Simondon." Gilbert Simondon: Being and Technology. Orgs. Arne De Boever et al. Edinburgh University Press. 121-134.

MORTON, Timothy (2007). Ecology Without Nature: Rethinking Environmental Aesthetics. Cambridge MA: Harvard University Press.

NIETZSCHE, Friedrich (2009). Genealogia da Moral: Uma Polêmica. São Paulo: Companhia das Letras.

PASK, Gordon (1961). An Approach to Cybernetics. Londres: Hutchinson. (1959). "Physical Analogues to the Growth of a Concept." Mechanisation of Thought Processes. Coord. A. Uttley. H.M. Stationery Office. 877-922.

PICKERING, Andrew (2010). The Cybernetic Brain: Sketches of Another Future. Chicago: University of Chicago Press.

(2009). "Beyond Design: Cybernetics, Biological Computers and Hylozoism." Synthese 168: 469-91.

PURSGLOVE, David (1960). "Fluid 'Transistor' Circuits May Rival Electronics." Science and Mechanics: 81-84.

RAY, Partha Pratim (2010). "The Green Grid Saga: a Green Initiative to Data Centers." Indian Journal of Computer Science and Engineering 1.4: 333339.

REES, William E. (2014). "Sustainability vs. Resilience." resilience.org. 10 de abril de 2015 .

http://www.resilience.org/stories/2014-07-16/sustainability-vsresilience

SIMONDON, Gilbert (2009). La Individuación a la Luz de las Nociones de Forma $y$ de Información. Buenos Aires: La Cebra y Cactus.

(1998). "Sobre a Técno-Estética: Carta a Jacques Derrida." Tecnociência e Cultura: Ensaios Sobre o Tempo Presente. Coord. Hermetes Reis de Araújo. Tr. Stella Senra. São Paulo: Estação Liberdade. 253-266.

WEBSTER, Andy e Jon Bird (2008). "Better Living Through Electrochemistry?.” Arfful Ecologies: Art, Nature and Environment. Coord. Daro Montag. Festerman. 121-129.

(C) 2015 Guilherme Kujawski.

Licensed under the Creative Commons Attribution-Noncommercial-

No Derivative Works 4.0 International (CC BY-NC-ND 4.0). 